\title{
РАСПРЕДЕЛЕНИЕ ЗОЛОТА В ЭПИГЕНЕТИЧЕСКИХ ПОРОДНЫХ АССОЦИАЦИЯХ ЛЕБЕДИНСКОГО И СТОЙЛЕНСКОГО МЕСТОРОЖДЕНИЙ КМА
}

\author{
О. Г. Резникова, В. С. Кузнецов, П. С. Бойко \\ Воронежский государственный университет
}

Поступила в редакцию 2 июля 2019 г.

\begin{abstract}
Аннотация: при комплексном исследовании проб получены новые данные о содержании благородных металлов в изучаемых породных ассочиачиях, отобранных в разных типах пород эпигенетических ассоииаций, развитых в железистых квариитах Лебединского и Стойленского месторождений, установлено большое разнообразие самородного золота содержащего $\mathrm{Ag}$ с редкой примесью Си, и его связь с Те-Ві минералами, при полном отсутствии теллуро-висмутидов Аи. Преобладает самородное золото высокой пробности при довольно широких ее вариачиях.

Ключевые слова: железистые кварииты, межрудные сланиы, самородное золото, жилы, катаклазиты, сульфиды, теллуриды, висмутиды.
\end{abstract}

\section{DISTRIBUTION OF GOLD IN THE EPIGENETIC BREED ASSOCIATIONS LEBEDINSKY AND STOJLENSKY DEPOSITS OF KMA}

\begin{abstract}
: a complex researches tests obtained new data on the content of precious metals in the studied rock associations, collected from the different rock types of epigenetic associations developed in the ferruginous quartzites of Lebedinsky and Stojlensky deposits has a large variety Ag-containing with a rare impurity of $\mathrm{Cu}$ in native gold and its relationship to Te-Bi minerals, in the absence of tellur-bismuth Au. Native gold of high probity prevails, with its rather wide variations.

Key words: ferriterous quartzites, interore shales, native gold, vein, cataclasite, sulfides, tellur, bismuth.
\end{abstract}

\begin{abstract}
Введение
Эпигенетические сульфидсодержащие образования достаточно широко проявлены на месторождениях Курской магнитной аномалии (КМА). Их распределение определяется положением разрывных нарушений, контактов кварцитов и сланцев, а так же зон дробления и трещиноватости. Благородные металлы, как было установлено ранее $[1,2]$, имеют пространственную и генетическую связь с сульфидными минералами и их аналогами (теллуридами и висмутидами). Поэтому изучение золотоносности сульфидсодержащих эпигенетических породных ассоциаций Лебединского и Стойленского месторождений КМА представляет научную актуальность, так как золото в процессе попутной переработки кварцитов и межрудных сланцев, а также их отвалов (хвостохранилищ) может дать достаточно высокие содержания и, с учетом современных технологий $[3,4]$, выйти на рентабельный уровень.
\end{abstract}

\section{Объект исследования}

При проведении исследований золотоносности железистых кварцитов и межрудных сланцев осо- бое внимание уделялось действующим Стойленскому и Лебединскому месторождениям, которые являются крупнейшими на КМА и входят в Старооскольский рудный узел. Карьерами рассматриваемых месторождений вскрыты породы Коробковской свиты курской серии палеопротерозоя - верхняя и нижняя железорудные, а так же нижняя сланцевая подсвиты [5].

Эпигенетические типы породных ассоциаций

К эпигенетическим ассоциациями пород на рассматриваемых месторождениях можно отнести секущие жильные гидротермальные образования, катаклазиты и «лебединиты».

Гидротермальные проявления чаще всего представляют собой прожилки и жилы кварцевого, кварц-сульфидного, реже карбонат-кварцевого и карбонат-кварц-сульфидного состава, мощностью от 1-2 см редко до 2-5 м, а также редкие маломощные зоны и прожилки с пиритовой и пирит-пирротиновой вкрапленностью мощностью от нескольких мм до 2-8 см. Благородные металлы в этих зонах достигают достаточно высоких содержаний (от 0,045 г/т 
до 53,12 г/т (табл. 1)).

Kатаклазить преимущественно силикатномагнетитовые, в качестве цементирующего материала зачастую выступают сульфиды. Мощность таких зон может достигать 6 м.

«Лебединиты» - сульфидно-карбонат-магнетитовые образования мощностью от десятков см до нескольких м. Характеризуются преобладанием сульфидной минерализации над оксидной. Преобладает пирит (от 29-32 \% до 80-85 \%), количество пирротина колеблется от 1-1,5 \% до 3-5 \%, присутствует халькопирит, марказит.

Минералогическая особенность вышеописанных пород выражается в наличии магнетит-пиритовых сростков, включений магнетита и пирротина в пирите, дисперсных включений пирротина в магнетите, а так же в присутствии вкрапленного пирротина в составе руд, иногда с крупными (десятые доли мм) кристаллами магнетита в нем.

\section{Методы исследования и аналитические данные}

В ходе полевых работ в карьерах Стойленского и Лебединского месторождений были отобраны образцы вышеописанных породных ассоциаций для определения их золото-платиноносности. Большая часть проб анализировалась методом атомно-абсорбционной спектрометрии в лаборатории анализа минерального вещества ИГЕМ РАН (табл. 1), первичная пробоподготовка проводилась в лаборатории ВГУ. Наиболее перспективные, на наш взгляд, отправлялись в ООО ЦНТ Инструментс, г. СанктПетербург в виде технологических проб по 50 кг. Из этих проб, после предварительного опробования на $\mathrm{Au}, \mathrm{Pt}$ и Pd методом ICP-MS (табл. 1), были выделены собственные минеральные формы благородных металлов.

Наиболее представительные образцы дополнительно изучались с целью выявления минеральных форм благородных металлов (пробы 558Б, 556, С550). Во всех из них обнаружено самородное золото в достаточно больших количествах. Оно находится преимущественно в самородном состоянии, а также в виде сплавов [6].

Пробность самородного золота в пробе 558Б характеризуется широкими вариациями: от $553 \%$ до $878 \%$. Однако в этой пробе основная часть золота принадлежит узкому классу пробности - от $650 \%$ до $840 \%$. Средняя пробность в пробе $-780^{\circ} \%$ при 35 замерах (табл. 2).

Средние размеры золотин из пробы С-550 coставляют 20-45 мкм. Средняя пробность золота $880 \%$, лигатура - серебро, в пяти пробах обнаружена примесь меди. Как и в вышеописанном образце, в этой пробе преобладающим является высокопробное самородное золото. Оно находится как в свободной форме, так и в срастании с сульфидами (преимущественно пиритом), висмутом самородным и хедлиитом. Химические составы самородного золота приведены в табл. 3.
Таблица 1

Содержания благородных металлов в эпигенетических сульфидсодержаших ассоииациях пород ([1] с дополнениями)

\begin{tabular}{|c|c|c|c|c|}
\hline Название породы & $\begin{array}{c}\text { № } \\
\text { обр. }\end{array}$ & $\begin{array}{l}\mathrm{Pt}, \\
\Gamma / \mathrm{T}\end{array}$ & $\begin{array}{l}\mathrm{Pd}, \\
\Gamma / \mathrm{T}\end{array}$ & $\begin{array}{l}\mathrm{Au}, \\
\Gamma / \mathrm{T}\end{array}$ \\
\hline \multirow{7}{*}{$\begin{array}{l}\text { Лебединит (актинолит- } \\
\text { биотит-карбонатная } \\
\text { сульфидизированная } \\
\text { порода; среднее содер- } \\
\text { жание сульфидов - } \\
57,2 \text { \%) }\end{array}$} & $144 / 2$ & 0,03 & 0,1 & 0,12 \\
\hline & 1ЛБ & 0,03 & 0,06 & 0,05 \\
\hline & $352 / 2$ & 0,03 & 0,14 & 0,19 \\
\hline & 122 & 0,02 & 0,04 & 0,1 \\
\hline & MT-7 & 0,12 & 0,14 & 0,1 \\
\hline & M27/2 & 0,07 & 0,31 & 0,1 \\
\hline & $353 a$ & 0,03 & 0,06 & 0,16 \\
\hline \multirow{4}{*}{$\begin{array}{l}\text { Катаклазит (среднее со- } \\
\text { держание сульфидов - } \\
54,7 \text { \%) }\end{array}$} & $313_{\ni}$ & 0,03 & 0,11 & 0,16 \\
\hline & 313 & 0,03 & 0,15 & 0,19 \\
\hline & $558 \mathrm{~b}^{*}$ & 0,02 & 0,03 & 0,96 \\
\hline & $532 / 2$ & 0,03 & 0,23 & 0,08 \\
\hline \multirow{6}{*}{$\begin{array}{l}\text { Жилы (кварцевые суль- } \\
\text { фидизированные с кар- } \\
\text { бонатом, биотитом, му- } \\
\text { сковитом и актинолитом; } \\
\text { среднее содержание } \\
\text { сульфидов - } 20 \text { \%) }\end{array}$} & $127-Э$ & 0,03 & 0,06 & 0,13 \\
\hline & 322 & 0,03 & 0,26 & 0,045 \\
\hline & 104 & 0,22 & 0,07 & 0,04 \\
\hline & $556^{*}$ & 0,02 & 0,05 & 53,12 \\
\hline & $570^{*}$ & 0,02 & 0,06 & 0,75 \\
\hline & C-550* & 0,05 & 0,02 & 0,3 \\
\hline
\end{tabular}

Примечание: анализы выполнены в лаборатории анализа минерального вещества (ЛАМВ) ИГЕМ РАН методом атомно-абсорбционной спектрометрии; *в аналитической лаборатории методом ICP-MS в ООО ЦНТ Инструментс.

Таблица 2

Распределение самородного золота по пробности (558Б)

\begin{tabular}{|c|c|c|c|c|}
\hline $\begin{array}{c}\text { Пробность } \\
\text { золота }\end{array}$ & $\begin{array}{c}550- \\
650 \%\end{array}$ & $\begin{array}{c}650- \\
750 \%\end{array}$ & $\begin{array}{c}750- \\
850 \%\end{array}$ & $>850 \%$ \\
\hline $\begin{array}{c}\text { Количество } \\
\text { зерен }\end{array}$ & 4 & 14 & 15 & 2 \\
\hline
\end{tabular}

Примечание: анализы выполнены в аналитической лаборатории методом ICP-MS в ООО «Инструментс».

Таблица 3

Химический состав самородного золота пробь С-550

\begin{tabular}{|c|c|c|c|c|c|c|c|}
\hline $\begin{array}{l}\text { № } \\
\text { ПП }\end{array}$ & $\mathrm{Au}$ & $\mathrm{Ag}$ & $\mathrm{Cu}$ & $\begin{array}{l}\text { № } \\
\text { ПП }\end{array}$ & $\mathrm{Au}$ & $\mathrm{Ag}$ & $\mathrm{Cu}$ \\
\hline 1 & 2 & 3 & 4 & 5 & 6 & 7 & 8 \\
\hline 1 & 99,17 & 0,83 & & 21 & 88,99 & 11,01 & \\
\hline 2 & 99,03 & 0,97 & & 22 & 88,55 & 11,45 & \\
\hline 3 & 98,95 & 1,05 & & 23 & 88,18 & 11,82 & \\
\hline 4 & 98,76 & 1,24 & & 24 & 87,42 & 12,58 & \\
\hline 5 & 98,25 & 1,75 & & 25 & 87,05 & 12,95 & \\
\hline 6 & 98,18 & 1,82 & & 26 & 86,63 & 13,37 & \\
\hline 7 & 97,64 & 2,36 & & 27 & 86,07 & 13,93 & \\
\hline 8 & 97,55 & 2,45 & & 28 & 85,82 & 14,18 & \\
\hline 9 & 97,31 & 2,69 & & 29 & 84,91 & 15,09 & \\
\hline 10 & 97,12 & 2,88 & & 30 & 82,38 & 16,32 & 1,3 \\
\hline 11 & 96,66 & 3,34 & & 31 & 82,62 & 17,38 & \\
\hline 12 & 96,44 & 3,56 & & 32 & 81,12 & 18,88 & \\
\hline 13 & 95,89 & 4,11 & & 33 & 78,86 & 21,14 & \\
\hline 14 & 95,35 & 4,65 & & 34 & 75,75 & 23,33 & 0,92 \\
\hline 15 & 91,14 & 6,23 & 2,63 & 35 & 76,00 & 24,00 & \\
\hline
\end{tabular}


Продолжение табл. 3

\begin{tabular}{|c|c|c|c|c|c|c|c|}
\hline 1 & 2 & 3 & 4 & 5 & 6 & 7 & 8 \\
\hline 16 & 92,37 & 7,63 & & 36 & 74,68 & 25,32 & \\
\hline 17 & 91,50 & 8,50 & & 37 & 70,99 & 29,01 & \\
\hline 18 & 90,81 & 9,19 & & 38 & 62,50 & 31,20 & 6,3 \\
\hline 19 & 89,93 & 10,07 & & 39 & 68,48 & 31,42 & 0,1 \\
\hline 20 & 89,53 & 10,47 & & 40 & 62,47 & 37,53 & \\
\hline
\end{tabular}

Примечание: анализы выполнены в аналитической лаборатории методом ICP-MS в ООО ЦНТ Инструментс.

Таблица 4 Химический состав самородного золота проба 556 по [2]

\begin{tabular}{|c|c|c|c|c|c|}
\hline № пп & $\mathrm{Au}$ & $\mathrm{Ag}$ & $\mathrm{Cu}$ & $\mathrm{Fe}$ & Сумма \\
\hline 1 & 79,65 & 19,1 & & & 98,75 \\
\hline 2 & 81,22 & 18,78 & & & 100 \\
\hline 3 & 79,51 & 19,45 & & 0,8 & 99,76 \\
\hline 4 & 82,34 & 17,6 & & & 99,94 \\
\hline 5 & 79,67 & 20,3 & & & 99,97 \\
\hline 6 & 80,08 & 19,9 & & & 99,98 \\
\hline 7 & 78,2 & 21,58 & & & 99,78 \\
\hline 8 & 75,56 & 24,12 & 0,34 & & 100,02 \\
\hline 9 & 78,29 & 19,66 & 0,78 & 0,85 & 99,58 \\
\hline 10 & 75,32 & 24,11 & & & 99,43 \\
\hline 11 & 69,55 & 30,33 & & & 99,88 \\
\hline 12 & 71,39 & 28 & & & 99,39 \\
\hline 13 & 79,35 & 20,65 & & & 100 \\
\hline 14 & 80,2 & 19,7 & & & 99,9 \\
\hline
\end{tabular}

Примечание: анализы выполнены в аналитической лаборатории методом ICP-MS в OOO ЦНТ Инструментс.
Пробность золотин в пробе 556 от $696 \%$ до $823 \%$ (табл. 4). Золото находится в ассоциации с теллуридами висмута (хедлиит, тетрадимит, жозеит В), висмутовыми минералами (висмутин, самородный висмут) [2], а так же с редким теллуратом - монтанитом и окисленным висмутом - бисмитом (рис. 1).

\section{Обсуждение результатов}

Анализируя полученные данные, можно отчетливо заметить, что в самородном золоте изучаемых пород преобладает примесь $\mathrm{Ag}$, примесь $\mathrm{Cu}$ встречается значительно реже в значительно меньших количествах. Для всех изученных образцов характерен широкий разброс $\mathrm{Au}$ по пробности. Во всех отобранных и проанализированных на минеральный состав благородных металлов проб самородное золото находится в ассоциации с теллуро-висмутовыми и сульфидными минералами, но отсутствуют теллуриды и висмутиды $\mathrm{Au}$ [2]. Все это являться отличительной особенностью именно эпигенетического типа породных ассоциаций в железорудных месторождениях.

\section{Выводы}

Выполненные специальные исследования эпигенетических ассоциаций пород, залегающих в железистых кварцитах и межрудных сланцах Курской магнитной аномалии (КМА) позволили существенно расширить сведения о распределении и концентрировании самородного золота [7-12]. А полученные новые данные о развитии в рудах Лебединского и Стойленского месторождений золоторудной минерализации и формах нахождения золота позволяют использовать реальные технологии их попутного извлечения из железорудных толщ КМА и их техногенных продуктов $[4,5,13]$.
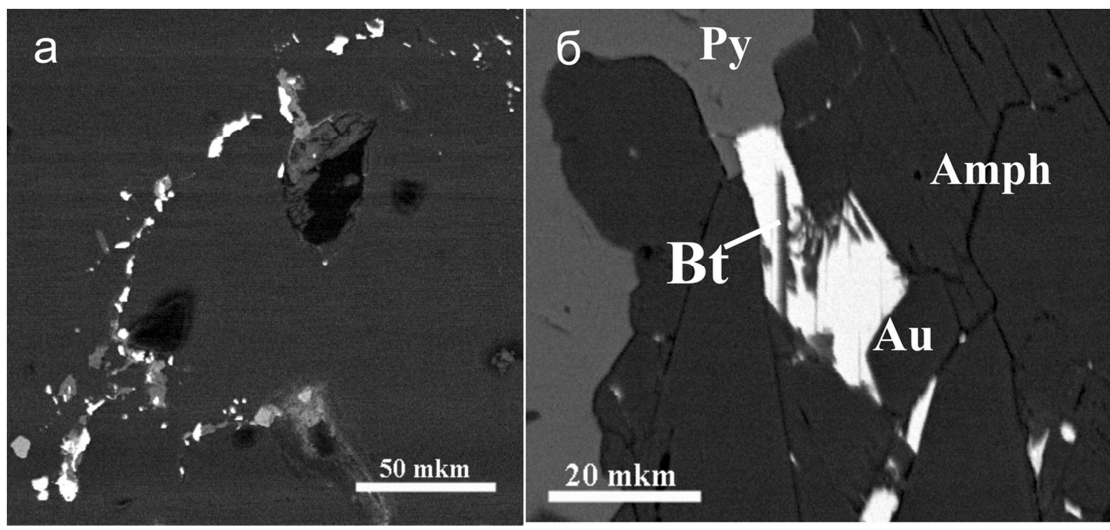

Puc. 1. Формы нахождения самородного золота и их ассоциации с сопутствующими минералами: а - золото-висмутовый прожилок в кварце, серое - окисленные минералы висмута; б - включения самородного золота в амфиболе в ассоциации с биотитом и пиритом.

\section{ЛИТЕРАТУРА}

1. Чернышов, Н. М. Типы, состав и генетические особенности золото-платинометалльного оруденения в железистых кварцитах Старооскольского рудного района КМА (Центральная Россия) / Н. М. Чернышов, О. Г. Резникова. - Воронеж. Издательский дом ВГУ, 2014. - 156 с.

2. Кузнецов, В. С. Золото-теллуро-висмутовая минерализация в различных типах благороднометалльного оруденения железистых кварцитов и межрудных сланцев курской серии КМА / В. С. Кузнецов, О. Г. Резникова // Вестник Воронежского гос. ун-та. Сер.: Геология. - 2018. - №2. - С. 107-114. 3. Матвиенко, В. Н. Кластеры - протоформа нахождения драгметаллов в рудах и минерализованных породах / В. Н. Матвиенко, Ю. Д. Калашников, В. А. Нарсеев // Руды и металлы. - 2004. - № 5. - С. 28-36.

4. Самосборка нанодисперсных форм платиноидов как 
метод их извлечения на примере золотосеребряных руд Милоградовского проявления (Приморский край) / Е.В. Ненахова [и др.] // Вестник Воронеж. гос. ун-та. Сер.: Геология. - 2018. - № 4. - С. 102-106.

5. Орлов, В. П. Железные руды КМА / В. П. Орлов. - М.: Геоинформмарк. $-2001 .-616 \mathrm{c}$.

6. Чернышов, Н. М. Формы нахождения благородных металлов в разнотипных железистых кварцитах и их метасоматитах Лебединского и Стойленского месторождений (КМА) Н. М. Чернышов, О. Г. Резникова // Вестник Воронежского гос. ун-та. Сер.: Геология. - 2010. - №1. - С. 135-144.

7. Первые находки минеральных форм элементов платиновой группы в железистых кварцитах КМА (Центральная Россия) / Н. М. Чернышов [и др.] // Доклады РАН. - 2003. T. 391. - № 1. - С. 104-107.

8. Чернышов, Н. М. Особенности распределения и формы нахождения платиновых металлов и золота в железистых кварцитах КМА и их техногенных продуктах (Центральная Россия) / Н. М. Чернышов, В. М. Изоитко, С. П. Молотков // Платина России. Новые нетрадиционные типы платиносодержащих месторождений и рудопроявлений платиносодержащего сырья. - М.: ООО «Геоинформмарк». - 2005. T.VI. - C. 87-99.

\section{ФГБОУ ВО «Воронежский государственный университет»}

Резникова Ольга Григорьевна, кандидат геолого-минералогических наук, дочент кафедры минералогии, петрографии и геохимии

E-mail: reznikova@o@bk.ru

Тел.: +7 (473) $22 \overline{0} 7966$

Кузнецов Владислав Сергеевич, кандидат геолого-минералогических наук, дочент кафедры минералогии, петрографии и геохимии

E-mail: voronezhpodkl@inbox.ru

тел.: +7 (473) 2207966

Бойко Павел Сергеевич, кандидат геолого-инералогических наук, доиент кафедры минералогии, петрографии и геохимии

E-mail:plekhanov.lsk@mail.ru

тел.: +7 (473) 2207966
9. Чернышов, Н. М. О золотоносности пород и руд Стойленского месторождения / Н. М. Чернышов, В. С. Кузнецов, О. Г. Резникова // Воронеж Вестник Воронеж. гос. ун-та. Сер.: Геология. - 2009. - № 1. - С. 103-110.

10. Золотоносность Стойленского месторождения КМА (типы и состав благороднометалльного оруденения) / Н. М. Чернышов [и др.] // Руды и металлы. - 2009. - №6. C. $48-55$

11. Чернышов, Н. М Новые данные о минеральном составе благороднометалльного оруденения Стойленского железорудного месторождения КМА (Центральная Россия) / Н. М. Чернышов, В. С. Кузнецов, С. В. Петров // Доклады академии наук. - 2009. - Т. 428. - № 6. - С. 801-804.

12. Чернышов, Н. М Минеральные формы нахождения платиноидов и золота в железистых кварцитах Лебединского месторождения КМА (Центральная Россия) / Н. М. Чернышов, С. В. Петров // Вестник Воронеж. гос. унта. Сер.: Геология. - 2005. - № 2. -С. 31-38.

13. Шелехов, А. Н. Золото- и платиноносность железистых кварцитов Русской платформы и пути их практического использования в XXI веке / А. Н. Шелехов // Руды и металлы. - 1999. - №1. - С.123.

\section{Voronezh State University}

Reznikova O.G., Candidate of Geological and Mineralogical Sciences, Associate Professor of the Mineralogy, Petrography and Geochemistry Department

E-mail: reznikova_o@bk.ru

Tel.: +7 (473) 2207966

Kuznetsov V. S., Candidate of Geological and Mineralogical Sciences, Associate Professor of the Mineralogy, Petrography and Geochemistry Department

E-mail:voronezhpodkl@inbox.ru

Tel.: +7 (473) 2207966

Boyko P.S., Candidate of Geological and Mineralogical Sciences, Associate Professor of the Mineralogy, Petrography and

Geochemistry Department

E-mail:plekhanov.lsk@mail.ru

Tel. :+7 (473) 2207966 